\title{
Front Matter: Volume 10346
}

, "Front Matter: Volume 10346," Proc. SPIE 10346, Plasmonics: Design, Materials, Fabrication, Characterization, and Applications XV, 1034601 (12 September 2017); doi: 10.1117/12.2286381

SPIE Event: SPIE Nanoscience + Engineering, 2017, San Diego, California, United SPIE. States 


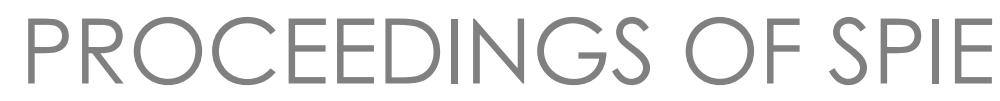

\title{
Plasmonics: Design, Materials, Fabrication, Characterization, and Applications XV
}

\author{
Din Ping Tsai \\ Takuo Tanaka \\ Editors
}

6-10 August 2017

San Diego, California, United States

Sponsored and Published by

SPIE 
The papers in this volume were part of the technical conference cited on the cover and title page. Papers were selected and subject to review by the editors and conference program committee. Some conference presentations may not be available for publication. Additional papers and presentation recordings may be available online in the SPIE Digital Library at SPIEDigitalLibrary.org.

The papers reflect the work and thoughts of the authors and are published herein as submitted. The publisher is not responsible for the validity of the information or for any outcomes resulting from reliance thereon.

Please use the following format to cite material from these proceedings:

Author(s), "Title of Paper," in Plasmonics: Design, Materials, Fabrication, Characterization, and Applications XV, edited by Din Ping Tsai, Takuo Tanaka, Proceedings of SPIE Vol. 10346 (SPIE, Bellingham, WA, 2017) Seven-digit Article CID Number.

ISSN: 0277-786X

ISSN: 1996-756X (electronic)

ISBN: 9781510611498

ISBN: 9781510611504 (electronic)

Published by

SPIE

P.O. Box 10, Bellingham, Washington 98227-0010 USA

Telephone +1 3606763290 (Pacific Time) · Fax +1 3606471445

SPIE.org

Copyright @ 2017 , Society of Photo-Optical Instrumentation Engineers.

Copying of material in this book for internal or personal use, or for the internal or personal use of specific clients, beyond the fair use provisions granted by the U.S. Copyright Law is authorized by SPIE subject to payment of copying fees. The Transactional Reporting Service base fee for this volume is $\$ 18.00$ per article (or portion thereof), which should be paid directly to the Copyright Clearance Center (CCC), 222 Rosewood Drive, Danvers, MA 01923. Payment may also be made electronically through CCC Online at copyright.com. Other copying for republication, resale, advertising or promotion, or any form of systematic or multiple reproduction of any material in this book is prohibited except with permission in writing from the publisher. The CCC fee code is $0277-$ $786 \times / 17 / \$ 18.00$.

Printed in the United States of America.

Publication of record for individual papers is online in the SPIE Digital Library.

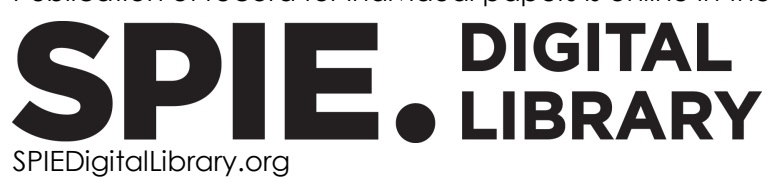

Paper Numbering: Proceedings of SPIE follow an e-First publication model. A unique citation identifier (CID) number is assigned to each article at the time of publication. Utilization of CIDs allows articles to be fully citable as soon as they are published online, and connects the same identifier to all online and print versions of the publication. SPIE uses a seven-digit CID article numbering system structured as follows:

- The first five digits correspond to the SPIE volume number.

- The last two digits indicate publication order within the volume using a Base 36 numbering system employing both numerals and letters. These two-number sets start with $00,01,02,03$, 04, 05, 06, 07, 08, 09, 0A, OB ... 0Z, followed by 10-1Z, 20-2Z, etc. The CID Number appears on each page of the manuscript. 


\title{
Contents
}

\author{
vii Authors \\ ix Conference Committee \\ xiii Introduction
}

THEORY, SIMULATION, AND DESIGN FOR PLASMONICS I

1034604 Comparison of the ultrafast hot electron dynamics of titanium nitride and gold for plasmonic applications [10346-3]

\section{PLASMONIC NANOSTRUCTURES AND NANOFABRICATION I}

1034606 3D plasmonic nanoarchitectures for extreme light concentration (Invited Paper) [10346-5]

1034607 Plasmonic nanogap structures studied via cathodoluminescence imaging [10346-6]

1034608 Electrostatic microcolumns for surface plasmon enhanced electron beamlets [10346-8]

\section{PLASMONIC SENSING}

10346 OD Design of a colorimetric sensing platform using reflection mode plasmonic colour filters [10346-13]

10346 OE Nanoporous gold decorated with silver nanoparticles as large area efficient SERS substrate [10346-14]

\section{CHARACTERIZATION FOR PLASMONICS}

10346 0J Numerical simulation of nonlocal optical response in light scattering by nanoparticle on the substrate [10346-20]

THEORY, SIMULATION, AND DESIGN FOR PLASMONICS II

10346 OP Rigorous expansion of electromagnetic Green's tensor of lossy resonators in open systems (Invited Paper) [10346-26] 
PLASMONIC APPLICATIONS II

10346 OW Tuning the characteristics of surface plasmon polariton nanolasers by tailoring the dispersion relation (Invited Paper) [10346-34]

RADIATION ENGINEERING

1034613 Fabrication and characterization of coupled ensembles of epitaxial quantum dots and metal nanoparticles supporting localized surface plasmons (Invited Paper) [10346-41]

1034615 UV fluorescence modification by aluminum bowtie nanoantennas [10346-43]

1034616 UV plasmonic enhancement through three dimensional nano-cavity antenna array in aluminum [10346-44]

1034617 Optical bistability and optical response of an infrared quantum dot hybridized to $\mathrm{VO}_{2}$ nanoparticle [10346-46]

NOVEL MATERIAL FOR PLASMONICS

$103461 \mathrm{H} \quad$ Modification of UV surface plasmon resonances in aluminum hole-arrays with graphene [10346-56]

PLASMONIC NANOSTRUCTURES AND NANOFABRICATION II

10346 IM Templated electrokinetic directed chemical assembly for the fabrication of close-packed plasmonic metamolecules [10346-62]

FUNDAMENTALS OF PLASMONICS II

10346 1V Plasmonic toroidal excitation with engineering metamaterials (Invited Paper) [10346-71]

POSTER SESSION

1034622 Resonance modes in unbalanced Mach-Zehnder interferometers embedded in plasmonic waveguides [10346-78]

$1034623 \quad$ Nano-metallic-planar-apex metamaterials [10346-79]

1034624 Flow-through nanohole array based sensor implemented on analogue smartphone components [10346-80]

1034625 Excitation of plasmonic waveguide modes using principles of holography [10346-81]

10346 2B Handheld highly selective plasmonic chem/biosensor using engineered binding proteins for extreme conformational changes [10346-88]

iv 
$103462 \mathrm{E}$ Plasmonic Fano resonances in novel nanostructure consisting of two rings with different diameter [10346-91]

$103462 G$ Polarizing filter based on anisotropic absorption of graphene ribbons with varying width [10346-93]

10346 2H Plasmonic waveguides based optical AND gate [10346-94]

10346 2J Polarization-independent multi-peak plasmonic absorber [10346-96]

$103462 \mathrm{M}$ Polarization dependent second harmonic generations of equilateral triangular Au nanorods at localized surface plasmon resonances [10346-99]

10346 2P Design of dielectric to plasmonic waveguide power transfer couplers [10346-102]

$103462 \mathrm{Q}$ Polarization independent asymmetric light absorption in plasmonic nanostructure [10346-103]

10346 2V Wideangle plasmonic filter for visible light applications [10346-108]

$103462 \mathrm{~W}$ Optics of multiple grooves in metal: transition from high scattering to strong absorption [10346-109]

$103462 X$ Analysis of near-field thermal energy transfer within the nanoparticles [10346-1 10]

1034630 SPP-assisted sub-wavelength reflection-type $\mathrm{THz}$ imaging with $\mathrm{THz}$ time-domain spectrometer [10346-113]

1034631 Orientational imaging of a single plasmonic nanoparticle using dark-field hyperspectral imaging [10346-114]

1034634 Efficient OAM generation at the nanoscale level by means of plasmonic vortex lens [10346-117]

1034639 Plasmonic detection of possible defects in multilayer nanohole array consisting of essential materials in simplified STT-RAM cell [10346-123] 
Proc. of SPIE Vol. 10346 1034601-6

Downloaded From: https://www.spiedigitallibrary.org/conference-proceedings-of-spie on 26 Apr 2023 Terms of Use: https://www.spiedigitallibrary.org/terms-of-use 


\section{Authors}

Numbers in the index correspond to the last two digits of the seven-digit citation identifier (CID) article numbering system used in Proceedings of SPIE. The first five digits reflect the volume number. Base 36 numbering is employed for the last two digits and indicates the order of articles within the volume. Numbers start with 00, 01, 02, 03, 04, 05, 06, 07, 08, 09, 0A, 0B...0Z, followed by 10-1Z, 20-2Z, etc.
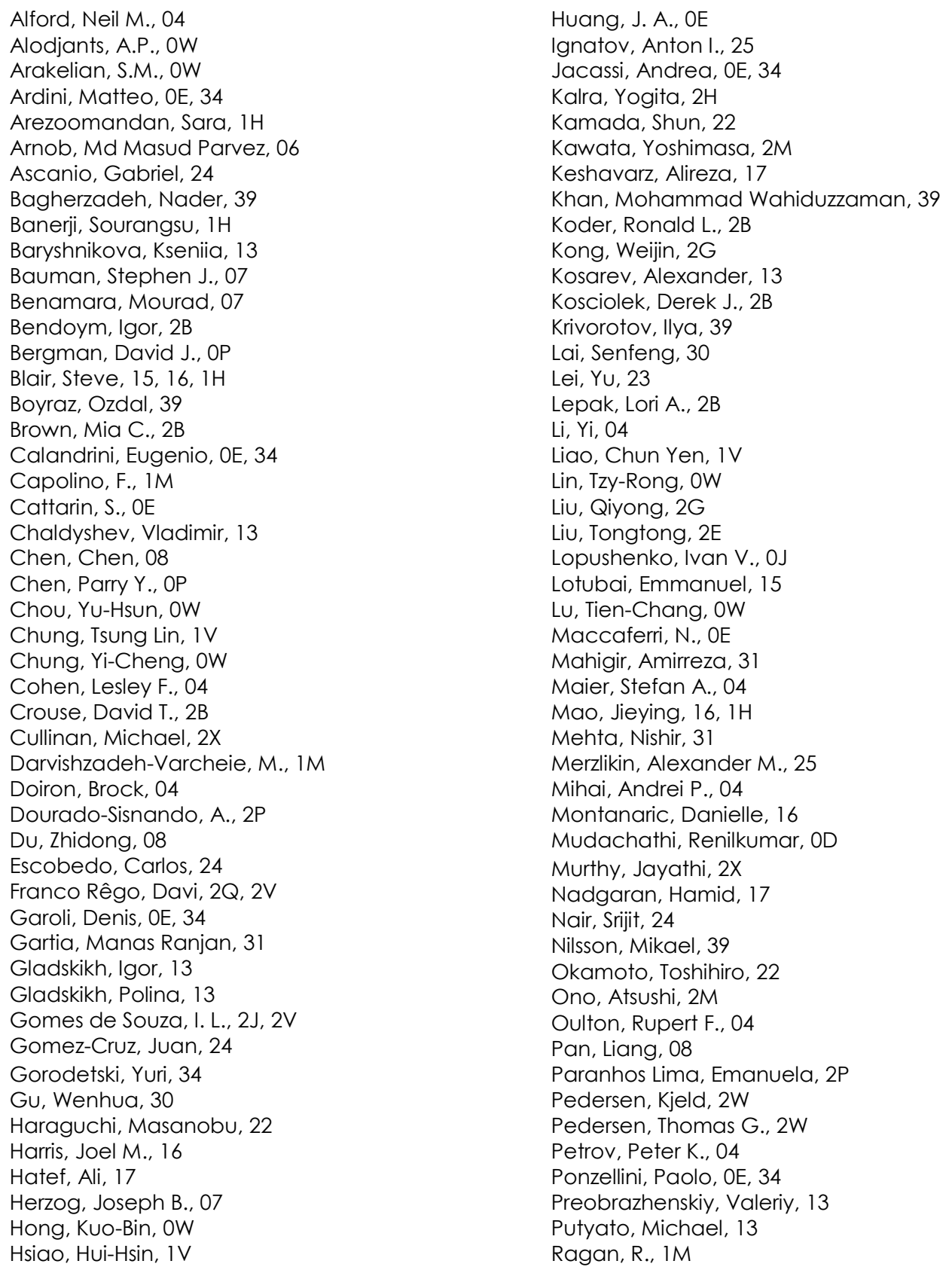
Rodriguez-Esquerre, Vitaly Felix, 2J, 2P, 2Q, 2V

Rubio Mercedes, C. E., 2P

Sadri-Moshkenani, Parinaz, 39

Sanchez-Sanchez, C., OE

Savinov, Vassili, $1 \mathrm{~V}$

Schnatz, Peter, 2B

Semyagin, Boris, 13

Sensale-Rodriguez, Berardi, $1 \mathrm{H}$

Shankhwar, Nishant, 2H

Shi, Yusen, 2E

Shih, Wei-Chuan, 06

Shumaker-Parry, Jennifer S., 16

Sinha, Ravindra Kumar, $2 \mathrm{H}$

Sivan, Yonatan, OP

Skjølstrup, Enok J. H., 2W

Sonar, Ajay, 2B

Søndergaard, Thomas, $2 \mathrm{~W}$

Stevenson, Peter, 16

Sugita, Atsushi, $2 M$

Sun, Peng, 2G

Tanaka, Takuo, OD

Thrift, W. J., IM

Tomer, Sonia, $2 \mathrm{H}$

Tong, Qing, 23

Toropov, Nikita, 13

Tsai, Din Ping, $1 \mathrm{~V}$

Vartanyan, Tigran, 13

Veronis, Georgios, 31

Wang, Haiwei, 23

Wang, Yunshan, 15, 16, 1H

Wei, Dong, 23

Wu, Pei Ru, $1 \mathrm{~V}$

Wu, Pin Chieh, IV

Wu, Wen, 30

Wu, Yanghui, 30

Xia, Feng, 2E

Xie, Changsheng, 23

Xin, Zhaowei, 23

Yan, Qigeng, 07

Yogo, Hirofumi, 2M

Yu, Edward T., $2 X$

Yuksel, Anil, $2 X$

Yun, Maojin, 2E, 2G

Zamani, Naser, 17

Zambrana-Puyalto, Xavier, 34

Zhang, Xinyu, 23

Zhao, Fusheng, 06

Zhao, Qiancheng, 39

Zheludev, Nikolay I., $1 \mathrm{~V}$

Zilio, Pierfrancesco, 34 


\section{Conference Committee}

Symposium Chairs

Harry A. Atwater Jr., California Institute of Technology (United States)

Nikolay I. Zheludev, Optoelectronics Research Centre

(United Kingdom) and Nanyang Technological University

(Singapore)

Symposium Co-chairs

James G. Grote, Air Force Research Laboratory (United States)

David L. Andrews, University of East Anglia (United Kingdom)

Conference Chairs

Din Ping Tsai, National Taiwan University (Taiwan)

Takuo Tanaka, RIKEN Center for Advanced Photonics (Japan)

Conference Program Committee

Martin Aeschlimann, Technische Universität Kaiserslautern (Germany) Harry A. Atwater Jr., California Institute of Technology (United States)

David J. Bergman, Tel Aviv University (Israel)

Allan D. Boardman, University of Salford (United Kingdom)

Che Ting Chan, Hong Kong University of Science and Technology (Hong Kong, China)

Yun-Chorng Chang, Academia Sinica (Taiwan)

Harald W. Giessen, Universität Stuttgart (Germany)

Jean-Jacques Greffet, Institut d'Optique Graduate School (France)

Naomi J. Halas, Rice University (United States)

Martti Kauranen, Tampere University of Technology (Finland)

Fritz Keilmann, LASNIX (Germany)

Dai-Sik Kim, Seoul National University (Korea, Republic of)

Laurens K. Kuipers, FOM Institute for Atomic and Molecular Physics

(Netherlands)

Mikhail Lapine, The University of Sydney (Australia)

Ai Qun Liu, Nanyang Technological University (Singapore)

Olivier J. F. Martin, Ecole Polytechnique Fédérale de Lausanne

(Switzerland)

Peter Nordlander, Rice University (United States)

Lukas Novotny, University of Rochester (United States)

Vahid Sandoghdar, ETH Zürich (Switzerland)

George C. Schatz, Northwestern University (United States) 
Tigran V. Shahbazyan, Jackson State University (United States)

Vladimir M. Shalaev, Purdue University (United States)

Gennady B. Shvets, Institute for Fusion Studies (United States)

Niek F. van Hulst, ICFO - Institut de Ciències Fotòniques (Spain)

Hongxing $X \mathbf{U}$, Wuhan University (China)

Nikolay I. Zheludev, Optoelectronics Research Centre

(United Kingdom) and Nanyang Technological University

(Singapore)

Joseph Zyss, Ecole Normale Supérieure de Cachan (France)

\section{Session Chairs}

1 Theory, Simulation, and Design for Plasmonics I

Otto L. Muskens, University of Southampton (United Kingdom)

2 Plasmonic Nanostructures and Nanofabrication I

Alessandro Alabastri, Rice University (United States)

3 Plasmonic Applications I

Takuo Tanaka, RIKEN Center for Advanced Photonics (Japan)

$4 \quad$ Plasmonic Sensing

Chih-Ming Wang, National Dong Hwa University (Taiwan)

5 Characterization for Plasmonics

Yun-Chorng Chang, Research Center for Applied Sciences Academia Sinica (Taiwan)

6 Novel Concepts of Plasmonics

Simeon Bogdanov, Purdue Univ. (United States)

7 Theory, Simulation, and Design for Plasmonics II

Nobuyuki Takeyasu, Okayama University (Japan)

8 Metamaterials and Metasurfaces I

Yung-Chiang Lan, National Cheng Kung University (Taiwan)

9 Plasmonic Applications II

Yung-Chiang Lan, National Cheng Kung University (Taiwan)

10 Nonlinear and Ultrafast Phenomena I

Min-Hsiung Shih, Academia Sinica (Taiwan)

11 Radiation Engineering

Pin Chieh Wu, Research Center for Applied Sciences - Academia Sinica (Taiwan) 
12 Fundamentals of Plasmonics I

Keiji Sasaki, Hokkaido University (Japan)

13 Metamaterials and Metasurfaces II

Shangjr Gwo, National Tsing Hua University (Taiwan)

14 Novel Material for Plasmonics

Yehiam Prior, Weizmann Institute of Science (Israel)

15 Plasmonic Nanostructures and Nanofabrication II

Stephan Link, Rice University (United States)

16 Nonlinear and Ultrafast Phenomena II

Hui-Hsin Hsiao, National Taiwan University (Taiwan)

17 Fundamentals of Plasmonics II

Yun-Chorng Chang, Research Center for Applied Sciences Academia Sinica (Taiwan)

18 Plasmonic Applications III

Pin Chieh Wu, Research Center for Applied Sciences - Academia Sinica (Taiwan) 
Proc. of SPIE Vol. 10346 1034601-12 Downloaded From: https://www.spiedigitallibrary.org/conference-proceedings-of-spie on 26 Apr 2023
Terms of Use: https://www.spiedigitallibrary.org/terms-of-use 


\section{Introduction}

This proceedings volume contains papers presented at the 2017 SPIE Optics + Photonics conference on Plasmonics: Design, Materials, Fabrication, Characterization, and Applications XV held in San Diego, California, 6-10 August 2017. The aim of the conference was to bring together specialists from diverse research areas and to provide a forum for the exchange of information on the latest progress in plasmonics to accelerate their applications and to look at the direction in which research in this field is leading us.

The conference was divided into 18 sessions. In the first session, papers were related to theory, simulation, and design for plasmonics, such as plasmoninduced hot carrier generation and applications, novel numerical method for electron energy-loss spectroscopy calculation: EELS-FDTD, comparison of the ultrafast hot electron dynamics of titanium nitride and gold for plasmonic applications, and enabling new regimes of nanoparticle resonances through beam engineering.

The second session was related to plasmonic nanostructures and nanofabrication, including 3D plasmonic nanoarchitectures for extreme light concentrating, plasmonic nanogap structures studied via cathodoluminescence imaging, and electrostatic microcolumns for surface plasmon enhanced electron beamlets.

The third session was plasmonic applications, including tunable plasmonics and metasurfaces for applications in optical switching and space technology, measurement of stokes parameters using plasmonic metasurface, and plasmon resonance sensors for compact plasmonic integrated devices.

The fourth session dealt with plasmonic sensing: metal-dielectric resonances in tip silicon metasurfaces and SERS based nanosensors, design of a colorimetric sensing platform using reflection mode plasmonic color filters, nanoporous gold decorated with silver nanoparticle as large area efficient SERS substrate, refractive index sensing with graphene plasmons, and labeling and imaging brain tumor cells with Raman tags.

The fifth session was on characterization for plasmonics, such as ultra-thin transition metal nitrides for plasmonic applications, light twists around plasmonic nanowires, numerical simulation of nonlocal optical response in light scattering by nanoparticle on the substrate, and revealing the femtosecond dynamics of metallic and molecular nanostructures.

The sixth session's topic was novel concepts of plasmonics, including mimicking general relativity through plasmonic spin Hall effect and novel platforms for plasmonics. 
The seventh session was devoted to theory, simulation, and design for plasmonics as well as including surface plasmon manipulated Smith-Purcell radiation on metallic periodic and gradient gratings, instantaneous spatial variation of Green's tensor in complex nanostructures via eigenmode expansion, plasmon-exciton energy transfer in nanoparticle-molecule aggregates, and light control metasurfaces with randomly dispersed silver nanoparticles.

The eighth session was related to metamaterials and metasurfaces, including new material platforms for dielectric nanoantennas and metasurfaces and multimode metasurfaces: from direct observation of the phase front to advanced optical functions.

The ninth session was also about plasmonic applications: surface plasmon polaritons for opto-mechanical control of nanoparticles, tuning the characteristics of surface plasmon polariton nanolasers by tailoring the dispersion relation, ultrafast carrier dynamics in bimetallic nanostructures-enhanced methylammonium lead bromide perovskites, enhanced photovoltaics in metamaterial devices using transparent conducting oxides, and infrared localized surface plasmon polariton nanostructures for various applications.

The tenth session was nonlinear and ultrafast phenomena: plasmonic nonlinear optical components, femtosecond controlling mechanism of surface plasmon polaritons, and adiabatic nanofocusing in hybrid gap plasmon waveguides.

The eleventh session was radiation engineering. We had papers presented on fabrication and characterization of coupled ensembles of epitaxial quantum dots and metal nanoparticles supporting localized surface plasmons, in-plane plasmonic antenna arrays resolve nanoscopic phase separation in model lipid membranes, UV fluorescence modification by aluminum bowtie nanoantennas, UV plasmonic enhancement through three dimensional nano-cavity antenna array in aluminum, and optical bistability and optical response of an infrared quantum dot hybridized to VO2 nanoparticle.

The twelfth session was fundamentals of plasmonics, which included topological features of plasmon polaritons, excitation of dark modes in plasmonic clusters by focused cylindrical vector beams, and suppression of infrared absorption in nanostructured metals by controlling Faraday inductance and electron path length.

The thirteenth session was also on metamaterials and metasurfaces: functional multi-layered composite metasurfaces, light tunable Fano resonnance in metaldielectric multilayer structures, and plasmonic nano-shaping and nanomanipulation.

The fourteenth session was novel material for plasmonics: nonlinear optics based on hybrid 2D semiconductor-plasmonic metasurfaces, optical transition and amplification of organic phosphor coupling with graphene plasmon, modification of UV surface plasmon resonances in aluminum hole-arrays with graphene, and 
resonant coupling between molecular vibrations and localized surface plasmon resonance of faceted metal oxide nanocrystals.

The fifteenth session dealt with plasmonic nanostructures and nanofabrication as well, including self-assembly for plasmonic structures on large scale, plasmonic nanoparticle lithography, electrohydrodynamic flow as a driving force for the directed chemical assembly of plasmonic meta-molecules, and large-scale nanofabrication of three-dimensional chiral nanostructures using a method combining nanospherical-lens lithography and hole mask lithography.

The sixteenth session was also devoted to nonlinear and ultrafast phenomena, such as ultrafast nonlinearities of semiconductor metasurfaces, grapheneplasmon lenses for enhanced harmonic generation, nonlinear plasmonic sensing with nanographene, and extreme nonlinear plasmonic phenomena in nanostructured graphene.

The seventeenth session was also focused on fundamentals of plasmonics. We had papers presented on ultrafast dynamics of plasmonic nanostructures, necklace beams in engineered nonlinear media, and plasmonic toroidal excitation with engineering metamaterials.

The eighteenth session was also related to plasmonic applications, including catching light in-flight: reshaping nanosecond laser pulses using active metasurfaces, a three-dimensional negative index medium and a miniature surface plasmon polariton amplitude modulator, giant nonlinearity arising from the vertical split ring resonators, and periodic metal nanoparticle arrays for largearea enhanced light-trapping.

\section{Din Ping Tsai Takuo Tanaka}


Proc. of SPIE Vol. 10346 1034601-16

Downloaded From: https://www.spiedigitallibrary.org/conference-proceedings-of-spie on 26 Apr 2023 Terms of Use: https://www.spiedigitallibrary.org/terms-of-use 